\title{
Decision support platforms for climate change adaptation: an overview and introduction
}

\author{
Jean P. Palutikof ${ }^{1}$ (D) $\cdot$ Roger B. Street $^{2} \cdot$ Edward P. Gardiner $^{3}$ \\ Received: 22 August 2018 / Accepted: 16 April 2019 / Published online: 6 May 2019 \\ (C) The Author(s) 2019
}

\section{Introduction}

The research literature on climate change adaptation has increased strongly in recent years, (Haunschild et al. 2016). Burkett et al. (2014) recorded 4239 publications in five languages containing the search terms "climate change" and "adaptation" in the title, abstract or keywords in the decade 2001-2010 compared with 20 in the decade 1981-1990. Despite this growth in research output, it remains the case that adaptation is essentially a practical activity, carried out in response to or in anticipation of the impacts of climate change (Tompkins et al. 2010; Corfee-Morlot et al. 2011), or in response to policy and investment requirements (EEA 2013; TCFD 2017).

The adaptation process is not necessarily undertaken by people for whom climate change is a central concern (Porter and Dessai 2017). A typical adaptor might be, for example an environmental manager based in a local authority whose primary responsibility is to oversee waste disposal and street lighting, who has been charged to ensure that the community and its assets are resilient to climate change (Measham et al. 2011; McClure and Baker 2018). Key barriers and drivers for such actors are listed in Table 1.

To address the needs of adaptors, online resources have emerged that provide information and guidance in support of adaptation. Earlier resources had the primary goal of delivering climate and climate change data from observations and modelling experiments to inform policy- and decision-makers about past, present, and future climate conditions (e.g. Hulme and Jenkins 1998; Hulme et al. 2002). More recent examples of climate data provision, often together with guidance on their use, include for the UK (Murphy et al. 2010), British Columbia

This article is part of a Special Issue on 'Decision Support Tools for Climate Change Adaptation' edited by Jean Palutikof, Roger Street, and Edward Gardiner.

Jean P. Palutikof

j.palutikof@griffith.edu.au

1 National Climate Change Adaptation Research Facility, Griffith University, Gold Coast, Australia

2 Environmental Change Institute, Oxford University, Oxford, UK

3 Collabralink Technologies, Inc. Contractor to Climate Program Office, National Oceanic and Atmospheric Administration, Asheville, USA 
Table 1 Barriers and drivers of climate adaptation

$\begin{array}{ll}\begin{array}{l}\text { Barriers } \\ \text { Lack of centrality } \\ \text { Lack of knowledge } \\ \text { Lack of time }\end{array} & \begin{array}{l}\text { Adaptation to climate change is not a focus of their employment. } \\ \text { He or she has limited knowledge of climate change. } \\ \text { He or she has limited time to apply to the issue of climate change and to learn } \\ \text { new information. } \\ \text { Financial resources to devote to adaptation, at least in the early, risk scoping, } \\ \text { stage, may be limited. }\end{array} \\ \begin{array}{l}\text { Drivers } \\ \text { Previous experience }\end{array} & \begin{array}{l}\text { An individual, organisation, or community may have experienced a climate-related } \\ \text { hazard in the past and therefore may have become motivated to improve } \\ \text { resilience to similar disturbances. } \\ \text { Awareness of climate-related hazards and shifting probabilities motivates } \\ \text { investigation of resilience options. } \\ \text { Community stakeholders may demand action on climate adaptation for reasons } \\ \text { that are external to the operating plan of a given agency or employee. }\end{array} \\ \text { Community preference } \\ \begin{array}{c}\text { The user may be required to explore the exposure and vulnerability of his/her } \\ \text { incentives }\end{array} \\ \begin{array}{l}\text { organisation, for example a requirement specified by legislation, or imposed } \\ \text { by shareholders. Alternatively, funding } \\ \text { may be available to support such activities }\end{array}\end{array}$

(Rodenhuis et al. 2009), the Netherlands (Lenderink et al. 2014), Switzerland (CH2011 2011), and Australia (CSIRO and Bureau of Meteorology 2015). These resources are often constructed by research centres, whether independent or within universities or national meteorological services. They are for the most part representative of "supply-driven" models of information delivery (Street 2016).

Climate change information can only take users to a certain point, i.e. understanding of present or possible future climate conditions which they can then use to assess impacts for areas or sectors of interest. This limitation is a frequent criticism of "top-down" approaches to climate adaptation (see Dessai and Hulme 2004), which begin with observed and modelled climate data before evaluating impacts and considering appropriate adaptation options. Research centres and meteorological services can more easily provide climate data than analyse impacts, so top-down approaches often require that organisations and decisionmakers themselves discover and articulate latent risks to their assets and resources, operations, products or services provided, or populations of concern. The information gap (between what climate researchers can easily provide and what decision-makers require) is compounded by uncertainties surrounding the climate data themselves. These uncertainties cascade through the assessment of impacts and adaptation options (Wilby and Dessai 2010). This means that users may find the top-down approach problematic.

A more bottom-up approach to guidance for adaptation has emerged to fulfil these information requirements using iterative, risk management methods that begin with the evaluation of exposure and vulnerability to specific hazards, lead to the assessment of risk, and result in the identification and implementation of adaptation options (Willows and Connell 2003). Climate data and scenarios are employed to better understand historical exposure and possible future changes that could cause stress or exacerbate hazards, all in support of the risk management process rather than as the starting point. Kwadijk et al. (2010) and Brown et al. (2012) provide detail on how this approach can be implemented.

Adaptation platforms (Fig. 1, and see Box 1 for definitions) have emerged that combine data with risk management frameworks, guidance, tools, and adaptation enablers (such as case studies and virtual or live engagements) to support adaptation. Adaptation platforms are often 
constructed and maintained by organisations with a specific mandate and funding to support adaptation. Examples include government-sponsored activities outlined in this Special Issue, for Europe (Hasse and Kind 2019; Laudien et al. 2019; Street et al. 2019), for Australia (Palutikof et al. 2019a), and for the USA (Gardiner et al. 2019). Though these examples emphasise government-funded entities, there are many private organisations and consultancies taking up the mantle of decision support for climate change adaptation, particularly in the USA.

Box 1 Definitions of terms as used in this paper

Adaptation platform: an enabling environment, equipping decision-makers with the data, tools, guidance, and information needed to adapt to a changing climate; content is commonly, but not necessarily, delivered online and may include facilitation of knowledge and capacity building through networking, for example via face-to-face or online forums, and peer-to-peer learning opportunities, for example workshops and case studies on adaptation planning and implementation.

Decision support tools: methods and other knowledge resources that facilitate decision-making for adaptation to climate change. These may be free-standing, or may be components of Adaptation Platforms. Examples include tools for costing adaptation options relative to the impacts avoided, such as cost-benefit analysis, guidance on identifying and assessing adaptation options and on monitoring and evaluation, and tools for data visualisation, such as a GIS-based tool.

Risk management framework: a structured process to assess risks (in this case from climate change and sea-level rise), to develop and implement strategies to manage those risks, and to monitor and evaluate the outcomes. The process is generally conceptualised as circular, allowing a return to risk assessment following the monitoring and evaluation step. It may be free-standing, may be accompanied by tools to facilitate the process (a decision support framework or system), or may be part of an Adaptation Platform.

Decision support framework (also known as a decision support system): a risk management framework for climate change adaptation together with the decision support tools necessary to implement the framework. The tools may include case studies demonstrating the application of the framework.

Climate experts involved in adaptation platform construction may have unrealistic expectations about decision-makers' ability and willingness to understand the jargon, complex scientific concepts, and limitations associated with climate change data (Hewitson et al. 2017; Porter and Dessai 2017; Moser et al. 2017), leaving users confused and, eventually, unwilling or unable to make use of the information provided (Hulme and Dessai 2008; Tang and Dessai 2012). One motivation behind building adaptation platforms is to address this cognitive barrier through strategies that include in-depth and continuing engagement and consultation with potential users to understand their needs (EEA 2015), simplicity of navigation through the platform, and use of accessible and (to the extent possible) jargon-free language (Lemos et al. 2012; Moss et al. 2013; Kirchhoff et al. 2013).

In this paper, we explore the history and characteristics of adaptation platforms: the extent to which they are relevant, usable, and useful (Prokopy et al. 2017), whether or not these attributes translate into sustained use (Reiter et al. 2018), barriers to take-up of adaptation platforms (Porter and Dessai 2017), and how these might be overcome. Finally, we summarise the content of this Special Issue and its contribution to the understanding of effective and sustainable decision support.

\section{Adaptation platforms in practice}

The United Nations Framework Convention on Climate Change (UNFCCC) came into force in 1994. Although the emphasis was very much on mitigation efforts, it required developed 


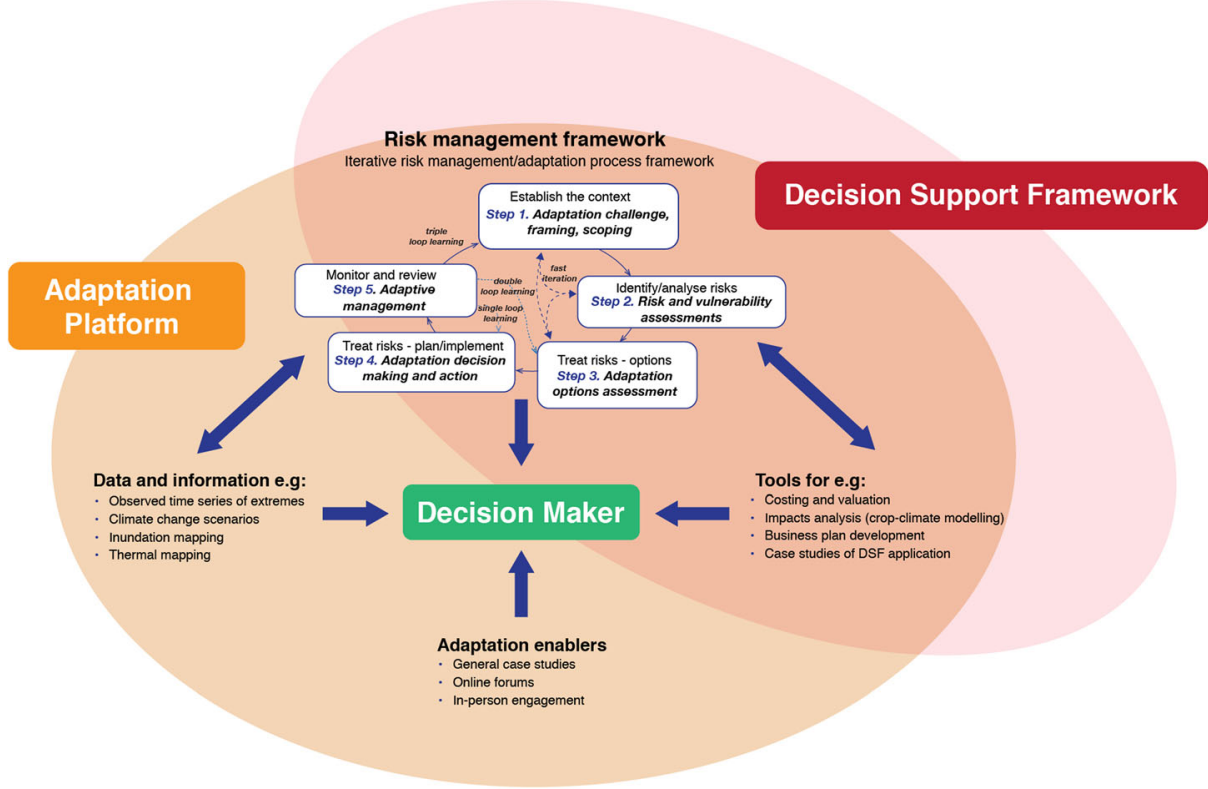

Fig. 1 Typical structure of an adaptation platform. The open system allows users to make use of parts or the whole, and for data, information, enablers, tools, etc. to be incorporated from elsewhere

countries to provide funds and assistance for adaptation in developing countries (Khan and Timmons 2013). In response, support for developing country adaptation began to emerge in the mid- and late 1990s, providing structured frameworks within which systematic adaptation planning and, to a lesser extent, action, could take place (Benioff et al. 1996; Feenstra et al. 1998). The provided advice was heavily influenced by the seven-step guidelines for assessment set out by Carter et al. (1994). A compendium of the tools that emerged in the 1990s in support of adaptation was produced by Stratus Consulting (1999) for the UNFCCC.

As UNFCCC adaptation policy evolved over time, decision support resources continued to emerge, always with an emphasis on developing countries, and generally delivered as pdf documents (UNFCCC 2002; Lim et al. 2004). An update to the Stratus Consulting compendium of tools was produced in 2005 (UNFCCC 2005). In the same year, the Nairobi Work Programme was set up under the UNFCCC to provide knowledge support on impacts, adaptation, and vulnerability, and in 2015, there was the release of the Adaptation Knowledge Portal (http://www4.unfccc.int/sites/nwp/Pages/Home.aspx accessed August 1, 2018), providing a growing compendium of knowledge resources for adaptation including case studies, tools, online portals and training materials.

In developed nations, specialised decision support for at-risk sectors, for example water resources (Diaz and Brown 1997), has been available since at least the early 1990s. The primary emphasis of early approaches was to evaluate exposure under contemporary climate variability regimes. The emergence and maturation of decision support followed the establishment of national-scale organisations such as the U.S. Global Change Research Program (mandated by the U.S. Congress in 1990), the UK Climate Impacts Programme (UKCIP, set up in 1997), and Ouranos in Canada (set up in 2001) (Perkins et al. 2007). The report by Willows and Connell (2003) for UKCIP has provided the 
basis for many of the risk assessment and management processes built into subsequent adaptation platforms (e.g. Prutsch et al. 2014; Tonmoy et al. 2019).

In the last decade, there has been a proliferation of resources in support of adaptation decision-making, both paper and online. Articles are beginning to appear which attempt to classify these resources in some way. For example, Hewitson et al. (2017) categorise 42 climate information websites (essentially, data delivery websites) according to 14 criteria. They find this formal typology insufficient to fully capture the experience of using these sites, and so also take a narrative approach. Their overall conclusion is that all the websites "grossly overestimate the ease of use" (Hewitson et al. 2017). Newman et al. (2017) reviewed 77 decision support systems for natural hazard risk reduction. They found only limited evidence for the success of decision support systems in practice and stressed the need for continuing evaluation of performance.

An emerging trend in decision support is towards commercialisation and "black box" approaches. Consulting companies are building commercial software either to assess risk, exposure, and vulnerability themselves or to enable others to do so. One example is the $C_{x}$ Climate Risk Analytics System from the USA (http://www.theclimateservice.com/ accessed 13 July 2018), which supports evaluation of the financial risks to businesses from climate using the U.S. Federal Emergency Management Agency's HAZUS methodology. A second is the Australian XDI Platform, which looks at cross dependencies from climate risks in buildings and infrastructure and the financial implications of these (http://xdi.systems/ accessed 13 July 2018). One drawback is that the internal structure of the software may be regarded as commercial-in-confidence, and so cannot be independently evaluated or adapted.

\subsection{Adaptation decision support in the literature}

To document the recent growth in resources for adaptation decision-making, we searched (Fig. 2) using the terms "climat* change" AND "adaptation" AND "decision support"

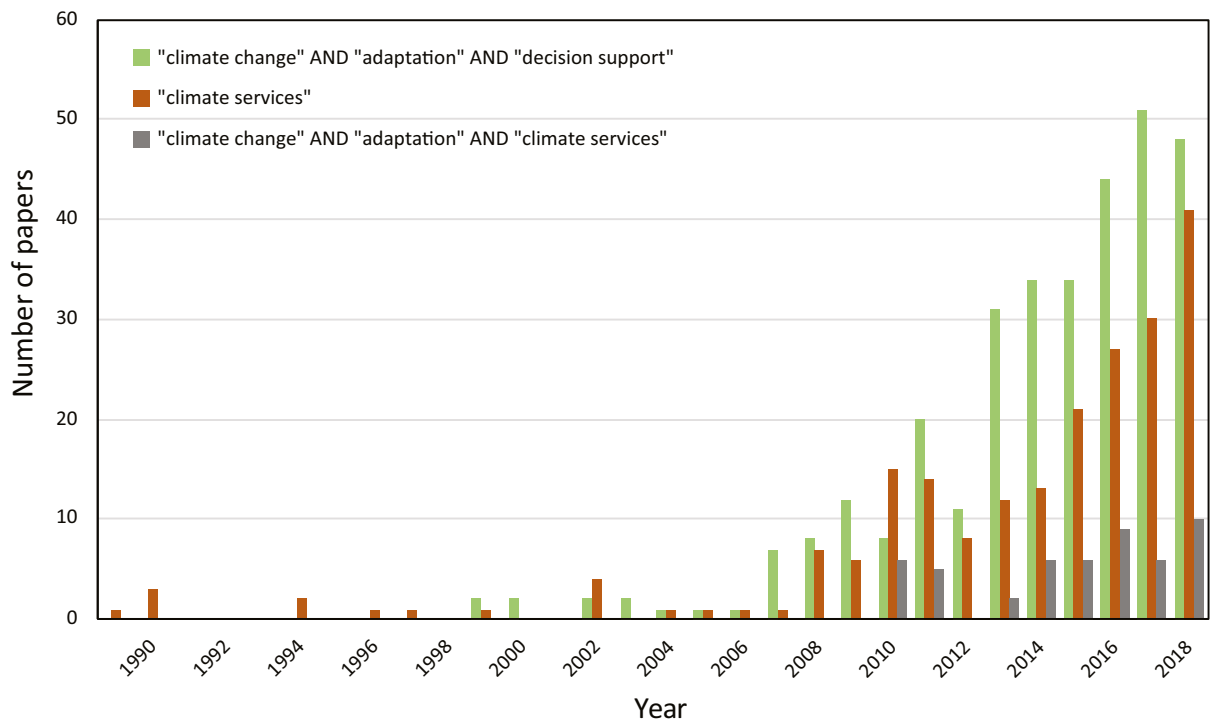

Fig. 2 Annual number of publications from Web of Science, 1989 to 2017. Search terms are shown in the top left-hand corner 
(starting in 2018, the search terminated when five consecutive years recorded no results). Because many accounts of decision support resources appear in the "grey literature" undocumented by Web of Science, this can only be an indication of activity. The search yielded a total of 325 papers in the period 1999 to 2018, 211 (72\%) of which have appeared in the last 5 years (2014-18) (Fig. 2). These 211 formed between 1.34 and $1.67 \%$ per annum of all papers using the terms "climat* change" AND "adaptation". Overall, three-quarters of the papers came from five countries: USA (29.8\%), Australia (12.9\%), Germany (12.0\%), England (11.7\%), and Canada (10.2\%). Street et al. (2015) identified 14 "national adaptation platforms" in Europe, two transnational, and one European-wide (Climate-ADAPT).

There is an overlap between the terminology around adaptation decision support resources and the use of the term "climate services". Climate services are defined by the World Meteorological Organisation as decision aids "derived from climate information that assist individuals and organizations in society to make improved ex-ante decision-making" and, more broadly, by Vaughan and Dessai (2014) as involving "the generation, provision, and contextualisation of information and knowledge derived from climate research for decision making at all levels of society". Whereas climate services often emerge from national meteorological services, decision support resources such as adaptation platforms are most commonly funded by governments seeking to encourage adaptation action and build preparedness. Figure 2 also shows the growth in the number of papers using the search term "climate services" in the period 1989-2018 (there were only 3 papers prior to 1989, all in 1984). In the context of climate change and adaptation, the first mention of "climate services" comes earlier than for "decision support", and growth is smoother. Nevertheless, $132(60 \%)$ of the total of 219 papers have appeared in the last 5 years, and 187 $(85 \%)$ in the last 10 years. We also used the search terms "climate change" AND "adaptation" AND "climate services", yielding 50 papers in the period 2010-18, with none appearing earlier.

\section{Structure of adaptation platforms}

A typical adaptation platform is likely to have four component parts:

- Guidance on the adaptation journey, very often conceptualised in a risk assessment and risk management framing

- Data and information to support adaptation

- Tools to support planning and decision-making, such as for costing adaptation options and monetary and non-monetary valuation of avoided impacts

- Adaptation "enablers", including as defined by Webb et al. (2019) as "the development of formal and informal communities of practice and knowledge brokering".

These components are shown in Fig. 1 and discussed briefly below. Together, they are intended to provide the user with everything required to undertake adaptation, from scoping the challenge through to monitoring and evaluating adaptation outcomes. 


\subsection{Guidance on how to undertake adaptation}

This will often be framed as a risk management process with guidance provided at each step (Fig. 1). The steps are broadly similar across a number of adaptation platforms: frame the problem, identify the risks, identify and evaluate options, prepare a plan, take action, and, finally, monitor and evaluate the results. The process allows for iteration depending on outcomes at each step, for example in CoastAdapt (Tonmoy et al. 2019) the outcome from the final step of monitoring and evaluation can lead to a return to the step of evaluating the options.

This approach raises two questions. First, in Table 1, we note that typical adaptors are timepoor and that adaptation may not be central to their prime responsibilities. This being the case, to what extent do the requirements of implementing a risk management process match the capacity and time available to the user? The Director of Emergency Management in Nashua, New Hampshire (USA) told one author (pers. comm):

I think for this to be successful, we need to integrate this into our planning for current hazard. I also feel like if I add a separate process, we may lose the support of our Collaborative [sic] planning team... Has this framework been integrated into a hazard mitigation planning process, or master planning process?

Very commonly, users will not carry out all the steps in a risk management framework for a single project in a structured approach. Reasons for this may include, first, the mismatch between, on the one hand, time available, and, on the other, the complexity of the actions needed to thoroughly implement risk management procedures. Second, does this relatively standard approach to risk assessment and management match the unusual features of adaptation planning in practice (i.e. from the users' perspectives)? For example, given the uncertainties and long timescales involved, how can one evaluate the performance of an adaptation action given that the risk it seeks to address may be many years in the future? There is a possibility that outcomes from an adaptation action may be judged successful in the short-term but maladaptive over long timescales, and vice versa.

In response to these challenges, rather than imposing a highly structured process, adaptation platforms provide guidance about identifying and formulating desired outcomes in order to approach climate adaptation practically and comprehensively. Prescriptive methods may be either unrealistic to implement (for instance, not accounting for sufficient complexity of individual cases) or even counter-productive (for instance, by imposing new requirements on decision-makers with limited resources). The use and evaluation of these types of adaptation platforms has demonstrated that non-prescriptive guidance is preferred.

In the last decade, adaptation has moved away from traditional predict-then-act approaches and towards iterative risk management framings that are effective in incorporating the deep uncertainties that surround climate change (Jones and Preston 2011). Partly in the continuing search for methods that address these deep uncertainties, the approach of "adaptation pathways" has attracted interest in recent years - a search of Web of Science using the terms "climate change" AND "adaptation pathways" showed a steady growth from two articles in 2010 to 32 in 2017. By defining threshold events as trigger points for decision-making and action, adaptation pathways remove some of the uncertainty around the timing and magnitude of climate change (Haasnoot et al. 2013; Ranger et al. 2013; Bosomworth et al. 2017; Lin et al. 2017). There have been few 
practical attempts to apply adaptation pathways approaches within a formal risk management framework; examples that do exist include for the Thames Barrier in the UK (Ranger et al. 2013), from the Philippines (Gilroy and Jeuken 2018), and from the Netherlands (Haasnoot et al. 2013). More commonly, adaptation pathways have been used as a means to enable community engagement and consultation (Barnett et al. 2014).

\subsection{Data and information to support adaptation}

Adaptation platforms are frequently a vehicle for data delivery, including climate change and sea-level rise scenarios, future coastal inundation mapping, and impacts of climate change. Platform builders will generally seek to understand and fulfil the data needs of their target audience using innovative, attractive, and appropriate delivery mechanisms. For example, the Climate Explorer in the U.S. Climate Resilience Toolkit uses a slider across a map of the USA to view present-day and future scenarios for a range of user-appropriate climate variables (see https://crt-climate-explorer.nemac.org/, accessed 9 July 2018).

Adaptation platforms also carry information to contextualise and support adaptation, for example on causes, observations, and impacts of climate change. Impacts of climate change are more easily documented at broad scales, but adaptation platforms seek to help decisionmakers focus on local issues. Solving this scale dependency is a central challenge for platform builders and users alike.

\subsection{Tools and methods to support planning and decision-making}

Recently, a range of analytical tools and methods has emerged to support decision-making around, for example timing and cost of action (Dittrich et al. 2016). These approaches include Dynamic Adaptive Policy Pathways (Haasnoot et al. 2013), Real Options Analysis (e.g. Sanderson et al. 2016), Info-Gap Decision Theory (e.g. Korteling et al., 2013), and Robust Decision-Making (e.g. Groves and Lempert, 2007). A practical issue is understanding how these differ, including in terms of the resulting decisions or outcomes. Hall et al. (2012) and Matrosov et al. (2013) compared Info-Gap Decision Theory and Robust Decision-making. Kwakkel et al. (2016) compared Robust Decision-making with Dynamic Adaptive Policy Pathways. More such comparative studies would be beneficial in terms of informing users about the ingredients, resource requirements and outcomes of the approaches so they can decide whether a particular approach is fit for purpose.

Tools may support a range of activities, from inundation mapping to support understanding flood risk, to costing adaptation (see, for example UKCIP 2004), to supporting local authorities to work effectively with consultants. The U.S. Climate Resilience Toolkit provides links to over 200 tools, many of which were not originally developed in support of climate change adaptation (https://toolkit.climate.gov/tools, accessed 9 July 2018). The UNFCCC Adaptation Knowledge portal provides information on and links to a number of such tools and methods.

\subsection{Adaptation enablers}

In consultation, potential users of adaptation platforms stress the value of peer-group collaboration and shared learning. Research results can be difficult to understand without detailed explanation due to unfamiliar terminology and/or methods for presenting scientific 
information. Building communities of practice and knowledge brokering can help to overcome such barriers (Webb et al. 2019). Peers who share their own experiences and knowledge can use familiar language and examples from familiar settings, thereby breaking down barriers to science or adaptation literacy. Adaptation platforms recognise this need so are actively exploring how best to build and facilitate those interactions. However, these interactions can be challenging. For example, Palutikof et al. (2019a) report that attempts to create an online forum for networking and knowledge and experience sharing within their platform met with only limited success.

Case studies are central to many adaptation platforms. These narratives provide location-, sector-, and adaptation-stage-specific exemplars of adaptation. CoastAdapt (Palutikof et al. 2019a) includes over 80 case studies, and the U.S. Climate Resilience Toolkit (Gardiner et al. 2019) over 140. Case studies can provide practitioners with confidence that their proposed actions are consistent with and potentially complementary to those taken by their peers and as such are not being undertaken in isolation but will form part of a broad initiative to address the impacts of climate change. However, it is notable that case studies to date generally focus on the early, capacity building and planning, stages of the risk management cycle, especially where the focus is adaptation to climate change going beyond building resilience to contemporary climate variability. The U.S. Climate Resilience Toolkit labels 62 of its 143 case studies $(43 \%)$ as being in the category of "Take action". Because these case studies represent the state of practice at the time the toolkit was assembled, they generally deal with climate variability rather than future change. In CoastAdapt, 22 of the 81 case studies (27\%) describe adaptation actions. Of these, six are focussed on extreme events and disaster management rather than climate change. Six describe adaptation overseas (two related to insurance schemes, three to coastal management, and one to water resources). This leaves ten Australian case studies (12\% of the total) describing actions to address current and future climate-five on coastal management, one on urban development, three on infrastructure, and one on nature conservation. This pattern is simply a reflection of where activity is focussed. Because case studies tend to report on adaptation that has already taken place, they will generally not describe current innovative developments. It is important that they are seen as vehicles for learning, and not as acceptance that the described activity is state-of-the-art adaptation.

\section{Evaluation of adaptation platforms}

A number of authors have laid out criteria against which the effectiveness of climate information delivery can be measured. These include saliency, credibility, and legitimacy (Cash et al. 2003); usefulness, usability, and credibility (Klink et al. 2017); and timely, accurate, credible, salient, and alignment with users' decision-scales (Lemos and Morehouse 2005). Essentially, these all revolve around the same considerations: that information should be tailored to the needs of the user in terms of content, style and presentation and should somehow be legitimised so that the user is confident in using it.

We would add that the user of an adaptation platform must be assured that a rigorous process for updating is in place, so that the information the platform carries is current and its use is legitimised. The process should include updating at regular intervals, and procedures for maintaining an accessible traceable account of what was updated, when and in what way. This is not a trivial task: how to update and link back in ways that do not confuse but inform the wide range of users (new and previous) is a major challenge. 
These considerations suggest that challenges exist in trying to develop an adaptation platform that is one-size-fits-all. The challenges although still substantial are somewhat reduced when the platform addresses the needs of a single sector such as water (Bojovic et al. 2018) or agriculture (Prokopy et al. 2017).

The evaluation process is complex and requires sustained and intensive engagement with users, providers and researchers. In consequence, there has been little work to evaluate (or even establish an effective process to evaluate) the extent to which adaptation platforms meet the above criteria to successfully address user needs (Swart et al. 2017). For example, Hewitson et al. (2017) found that in 25 out of 42 Climate Information Systems surveyed, decision-makers would struggle to navigate the site successfully, which they ascribed to unrealistic presumptions by developers about the technical abilities and conceptual understanding of users, and an over-reliance on jargon.

There has been some follow-up evaluation by platform developers (e.g. Mattern et al. 2018). Tracking site usage through Google Analytics is a straightforward and cost-effective approach commonly used to understand basic usage (Klink et al. 2017; Gardiner et al. 2019; Palutikof et al. 2019a), but it provides little or no indication of users' background, motivation for visiting the site, satisfaction levels, and use made of the accessed information and guidance. However, there are a few published examples of in-depth, structured, longer-term evaluations of the contribution of adaptation platforms. Newman et al. (2017) evaluated 77 decision support systems for natural hazard risk reduction in 101 papers and found that 28 were reportedly used beyond the case study described in the analysed paper. Klink et al. (2017) surveyed existing and potential users of their decision support tools for adaptation in agriculture. They found that $85-96 \%$ of respondents considered such tools to be relevant to their career and, of these, around half had used a decision support tool with climate information in the past and 94\% expressed willingness to use one in the future. Clar and Steurer (2018) surveyed a number of local authorities about the Adaptation Wizard (a UK adaptation platform) and Klimalotse (Germany based) and found that these were little known among local authorities, and that those who were aware of them considered them too comprehensive and too complex within the requirements of the current policy settings.

The Adaptation Wizard was developed by the UK Climate Impacts Program (UKCIP 2013) as a broad-based platform providing support for UK organisations seeking to adapt. The webpage (https://www.ukcip.org.uk/wizard/) has links to six test cases carried out to evaluate users' experiences with the Wizard. Table 2 summarises some of the findings, and points to three conclusions. First, the test cases are generally at the earlier stages of the adaptation process, evaluating their risks and adaptation options (i.e. most commonly the first three steps of the Adaptation Wizard). Second, the longest timeframe of interest to these organisations was the 2080 s, and many were interested in changes over the next 5-10 years, suggesting a strong disconnect between the climate change scenarios routinely produced by scientists for the end of the century and what users want and need. Finally, experiences using the platform were generally positive. In part, this was deemed to be due to the fact that the organisations were all provided with support to use the Wizard, either by the developers or by consultants hired by the developers. This meant that the organisations did not have to devote a large amount of time to become familiar with the Wizard, but were guided to navigate it efficiently.

Palutikof et al. (2019b) used a similar approach of 6-week test cases to evaluate the utility of the CoastAdapt platform. Out of 12 organisations involved, eight were either single local authorities or groups of authorities, two were aquaculture companies, one was an infrastructure (airport) operator, and one was a mutual finance company (see Table 2 in Palutikof et al. 


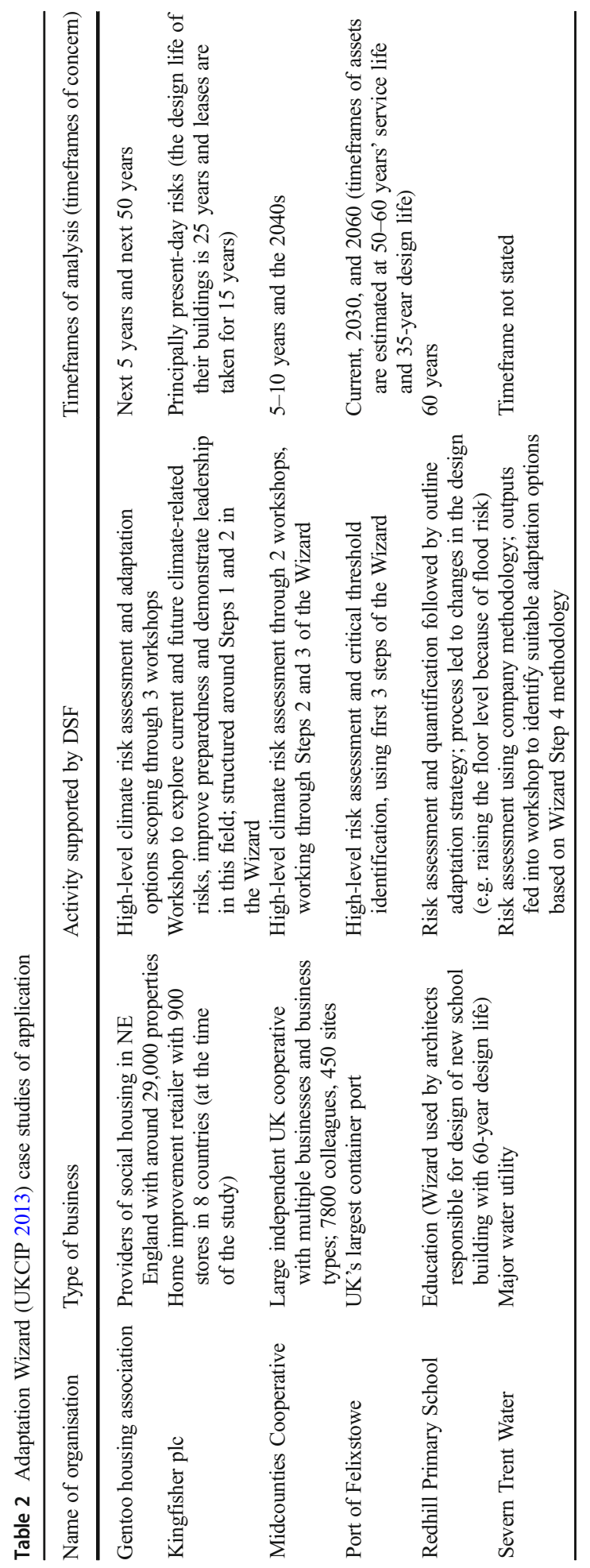


2019b). There are strong similarities between the Adaptation Wizard and CoastAdapt test cases. Again, test case organisations were at an early stage in the adaptation process: three used CoastAdapt to build awareness and capacity in their organisation, four undertook a first-pass risk assessment, two were seeking to understand how best to engage with their community prior to commencing adaptation planning, and three were in the process of preparing adaptation plans. The time scales of concern generally did not extend beyond the 2050 s, except in the case of the infrastructure operator, which expressed an interest in impacts up to 2070. All test case organisations were provided with an independent consultant, and experiences were generally positive, with feedback leading to some useful amendments to CoastAdapt.

During February-March 2015, a team from Antioch University analysed perception and use of the U.S. Climate Resilience Toolkit by 29 climate data end-users in, and/or serving, coastal communities from Norfolk, VA, to Rockland, ME (Abrash Walton et al. 2015). In rank order, the toolkit attributes of greatest value to participants were as follows: their direct interactions with the toolkit's program manager (62\%; see Davidson et al. 2015 for support of this finding); opportunities to network with other decision-makers, planners, and researchers who work with coastal communities (54\%); using the toolkit for decision support (46\%); receiving an orientation seminar (38\%); and the opportunity to share learning with others working with coastal communities (31\%). In another engagement, the Department of Homeland Security led an 8-hour discussion-based exercise at the University of Southern Maine in Portland, ME, on May 7 2015, with 57 participants. Participants noted the variety and number of tools available in the toolkit, and considered that they provide useful capabilities and information but still leave each community to conduct adaptation planning on its own. They valued the Steps to Resilience framework (Gardiner et al. 2019) but were confused when it did not provide prescriptive data or recommendations, for example for evaluation of vulnerability and risk. Some participants found the language and terminology of the toolkit and the Steps to Resilience framework to be obscure, technical, and specialised. Many indicated they were not subject-matter experts in climate science or adaptation planning. The quantity of information within the toolkit intimidated many participants. In addition, participants unanimously identified the need for technical assistance, specifically with visualisation tools and downscaling data. This feedback echoes that of Street et al. (2019) about desirable characteristics of decision support resources.

\section{Discussion}

In this paper, we have looked at adaptation platforms and their applications, concentrating on three examples-CoastAdapt from Australia, the Adaptation Wizard from the UK, and the U.S. Climate Resilience Toolkit. Each nation, and even regions within nations, poses distinct policy drivers that motivate users' interest in and adoption of these resources (see Table 1, lower section). While this is a small cross-section of applications, they make clear that extrinsic factors, such as policy or investment drivers, are important determinants of the efficacy of applying adaptation platforms to climate adaptation. Similarly, intrinsic factors, such as the nature of the relationships established between suppliers and practitioners, influence the adoption of platforms and their constituent elements (Fig. 1). 
Platforms and related resources to support climate change adaptation have become widely available in recent years, and examples can be found for most sectors and for different geographical locations, including coasts (Torresan et al. 2016; Lane et al. 2013) and rural areas (Cao et al. 2018; Nkoana et al. 2018). Despite the widespread availability of decision support resources, there is little understanding of their effectiveness - the extent to which they are useful to practitioners, and the extent to which they are used. It appears that tensions exist between the needs and goals of the funders, the builders, and the potential users of decision support resources, which can be characterised under three headings.

The first tension exists between the goals of funding bodies and the needs of practitioners. Funding bodies seek cost-effective and time-bounded ways to provide adaptation practitioners with information and support based on an understanding of their needs. Adaptation platforms, especially web-based platforms, are seen as an effective means of addressing this requirement. They can deliver information, data, and guidance, generally in attractive and accessible formats, tailored to the needs, abilities and expertise of users. However, if a project has a fixed end date, funding may terminate on completion and release of the decision support resource. Although there may have been extensive engagement and consultation with potential users during design and build, the long-term success of projects may be jeopardised if such engagement terminates with the project's funding. To maintain relevance in the longer term, funds must be available for updating, to provide training opportunities and to sustain engagement with users. If practitioners lack confidence in the credibility and legitimacy of a platform - that the information it delivers is current and credible in policy, practice and science terms - then they will cease to use it. This Special Issue provides examples of excellence in sustained management and updating of adaptation platforms, including regular updating such as occurs with the U.S. Climate Resilience Toolkit (Gardiner et al. 2019) and updating at intervals, such as with the Klimalotse (Hasse and Kind 2019).

The second tension is between what practitioners need to support their adaptation activity and what adaptation platforms deliver. Practitioners will adjust their adaptation activity to the context within which they operate, in particular, what is required of them by the regulatory and legislative context. This context can change within the span of time over which a project to produce a platform or decision support resource is conceived and executed. This means that a design for an adaptation platform laid out at the start of the build may need to be adapted during its development, as the original design may no longer be appropriate by the time the project is completed (Porter et al. 2015; Clar and Steurer 2018). For example, at the present time in Europe, current requirements on local authorities to adapt mean that the need is for targeted support for modest interventions, for example around cost-benefit analysis, rather than insisting on comprehensive system-wide approaches that the Adaptation Wizard and Klimalotse can support (Clar and Steurer 2018).

Finally, there is tension as a result of the differences in expectations of users, builders, and funders as to what decision support can and cannot actually provide. Many practitioners often go to adaptation platforms with the expectation that they will find instant solutions. Even a platform or tool that is tightly focussed on a particular problem, sector, or location requires some commitment of time and deliberation on the part of decision-makers in order to be effective. If practitioners are unable to make this commitment, then the most common solution is to hire a consultant. Although this represents a potential solution, it comes with the penalty that no corporate or in-house experience is created. This could be a significant penalty as adaptation is a continuous learning and improvement process with subsequent iterations required, so that more and more in-house knowledge and expertise is needed. 


\section{Conclusions}

Adaptation platforms have a valuable role to play, especially where the goal is to enhance communication and knowledge exchange between science, policy and practitioners to promote effective, comprehensive and staged adaptation to long-term climate change. That model of collaboration contrasts with targeted projects designed to address short-term risk. In order to ensure that the potential benefits of adaptation platforms are realised, three requirements that sit outside the design-construct-implement process need to be fulfilled. First, there needs to be comprehensive, independent, and long-term evaluation of the current applications of decision support resources, to understand how and why practitioners make use of them and to understand their limitations. This is a requirement which is widely stressed throughout the literature on adaptation decision support (Newman et al. 2017; Gardiner et al. 2019; Hasse and Kind 2019; Palutikof et al. 2019c). Second, extrinsic factors need to motivate practitioners to undertake comprehensive, long-term adaptation planning so they overcome its implicit inertia. Those factors might include policy requiring action, financial incentives, or social pressures (Table 1). Third, funding agencies need to accept that adaptation decision support resources require long-term funding to enable regular updating as science, risk management methods and adaptation options evolve. Long-term funding can also provide users with some level of "hand holding" support.

This Special Issue presents papers on decision support resources designed and built to address the comprehensive needs of adaptation practitioners. These examples are drawn from five countries, representing a diversity of experiences, regulatory environments, and solutions:

- CoastAdapt is designed to support coastal adaptation in Australia (Palutikof et al. 2019a; Tonmoy et al. 2019).

- The Adaptation Wizard is an early and comprehensive decision support resource for the UK (Street et al. 2019), and many subsequent adaptation platforms have taken its good practice as a starting point, with two examples described by Street et al. (2019).

- The U.S. Climate Resilience Toolkit (Gardiner et al. 2019) is a comprehensive platform representing capabilities and examples of adaptation support throughout the U.S. Federal Government. The toolkit also hosts its bespoke Climate Explorer-a tool that features frequently updated, innovative visualisations of hazard-relevant climate variables.

- Hasse and Kind (2019) describe the process to evaluate and update the Klimalotse, an adaptation platform for Germany, after several years of operation.

- Laudien et al. (2019) describe their adaptation platform Knowledge Portal for Spatial Adaptation for the Netherlands.

The Special Issue continues with a set of papers on challenges associated with the design and construction of online adaptation platforms, especially the need to ensure consultation and engagement from potential users. For example, two papers look at the consultation processes underlying the CoastAdapt design and build (Leitch et al. 2019; Palutikof et al. 2019b). Two papers look more broadly across the spectrum of platforms, their attributes, strengths, and weaknesses. Webb et al. (2019) conclude that adaptation platforms are capable of guiding users towards more systematic and coordinated approaches to adaptation, and hence are a key to embedding climate adaptation responses into the way business is done. Fünfgeld et al. (2019) focus on the health and social service sectors to explore how practitioners can be encouraged to use adaptation platforms and how, when guided to make a choice, their selection will meet their particular needs. 
A concluding paper seeks to pull together the conclusions from the Special Issue papers to explore how adaptation platforms can evolve in the future by proposing a set of guiding principles that would enhance usefulness of such resources to practitioners in the rapidly shifting world of adaptation.

Funders often expect that providing a web-based adaptation platform means that decisionmakers will use it and the resulting decisions and actions will be robust and appropriate. There is an expectation that the information will be relevant, usable, legitimate, and credible, and it will be used. The platform is often seen as providing a one-stop-shop for all targeted users. The difficulty arises from two perspectives. First, users are not homogenous nor are the challenges they face when planning or undertaking adaptation and, as such, a one-stop shop for all intended users may be difficult to provide. Second, availability does not necessarily mean that it will be used or that it is even seen by all intended users as providing relevant, usable, legitimate and credible support.

It is clear that, although potentially effective, regulatory, legislative and investment imperatives to adapt are insufficient. Considering the imperative and the nature of climate actions required, decision support resources such as adaptation platforms, along with investments of time and money, are needed for practitioners to undertake effective adaptation and build longterm institutional capacity that is consistent with the current and evolving adaptation challenge.

Open Access This article is distributed under the terms of the Creative Commons Attribution 4.0 International License (http:/creativecommons.org/licenses/by/4.0/), which permits unrestricted use, distribution, and reproduction in any medium, provided you give appropriate credit to the original author(s) and the source, provide a link to the Creative Commons license, and indicate if changes were made.

\section{References}

Abrash Walton A, Simpson M, Castriotta M (2015). U.S. Climate Resilience Toolkit road test: bridging the datapractice divide. Antioch University New England, Center for Climate Preparedness and Community Resilience, Faculty Articles 48, Keene, NH

Barnett J, Graham S, Mortreux C et al (2014) A local coastal adaptation pathway. Nat Clim Chang 4:1103-1108. https://doi.org/10.1038/NCLIMATE2383

Benioff R, Guill S, Lee J (1996) Vulnerability and adaptation assessments: an international handbook. Springer Netherlands. https://doi.org/10.1007/978-94-009-0303-6

Bojovic D, Giupponi C, Klug H et al (2018) An online platform supporting the analysis of water adaptation measures in the Alps. J Environ Plann Man 61:214-229. https://doi.org/10.1080/09640568.2017.1301251

Bosomworth K, Leith P, Harwood A, Wallis PJ (2017) What's the problem in adaptation pathways planning? The potential of a diagnostic problem-structuring approach. Environ Sci Pol 76:23-28. https://doi.org/10.1016/j. envsci.2017.06.007

Brown C, Ghile Y, Laverty M, Li K (2012) Decision scaling: linking bottom-up vulnerability analysis with climate projections in the water sector. Water Resour Res 48:W09537. https://doi.org/10.1029/2011WR011212

Burkett VR, Suarez AG, Bindi M et al (2014) Point of departure. In: Field CB, Barros, VR, Dokken DJ et al (eds) Climate Change 2014: Impacts, adaptation, and vulnerability. Part A: global and sectoral aspects. Contribution of Working Group II to the Fifth Assessment Report of the Intergovernmental Panel on Climate Change, Cambridge University Press, Cambridge, pp 169-194

Cao JJ, Li MT, Deo RC et al (2018) Comparison of social-ecological resilience between two grassland management patterns driven by grassland land contract policy in the Maqu, Qinghai-Tibetan Plateau. Land Use Policy 74:88-96. https://doi.org/10.10164/j.landusepol.2017.07.027

Carter TR, Parry ML, Harasawa H, Nishioka S (1994) IPCC technical guidelines for assessing climate change impacts and adaptations. Department of Geography, University College London and Center for Global Environmental Research, Ibaraki

Cash DW, Clark WC, Alcock F et al (2003) Knowledge systems for sustainable development. Proc Natl Acad Sci USA 100:8086-8091. https://doi.org/10.1073/pnas.1231332100 
CH2011 (2011) Swiss climate change scenarios CH2011. C2SM, MeteoSwiss, ETH, NCCR Climate, OcCC, Zurich

Clar C, Steurer R (2018) Why popular support tools on climate change adaptation have difficulties in reaching local policy-makers: qualitative insights from the UK and Germany. Environ Policy Gov 28:172-182. https://doi.org/10.1002/eet.1802 A

Corfee-Morlot J, Cochran I, Hallegatte S, Teasdale P-J (2011) Multilevel risk governance and urban adaptation policy. Clim Chang 104:169-197. https://doi.org/10.1007/s10584-010-9980-9

CSIRO, Bureau of Meteorology (2015) Climate change in Australia information for Australia's natural resource management regions: technical report. CSIRO and Bureau of Meteorology, Australia

Davidson EA, Suddick EC, Rice CW, Prokopy LS (2015) More food, low pollution (Mo Fo Lo Po): a grand challenge for the 21st century. J Environ Qual 44:305-311. https://doi.org/10.2134/jeq2015.02.0078

Dessai S, Hulme M (2004) Does climate adaptation policy need probabilities? Clim Pol 4:107-128

Diaz GE, Brown TC (1997) AQUARIUS: A modeling system for river basin water allocation. General Technical Report RM-GTR-299. Rocky Mountain Forest and Range Experiment Station, Fort Collins

Dittrich R, Wreford A, Moran D (2016) A survey of decision-making approaches for climate change adaptation: are robust methods the way forward? Ecol Econ 122:79-89. https://doi.org/10.1016/j.ecolecon.2015.12.006

EEA (2013) Adaptation in Europe: addressing risks and opportunities from climate change in the context of socio-economic developments. Environment Agency Report 3/2013, EEA, Copenhagen

EEA (2015) Overview of climate change adaptation platforms in Europe. In: European environment agency technical report 5/2015. EEA, Copenhagen. https://doi.org/10.2800/400414

Feenstra JF, Burton I, Smith JB, Tol RSJ (1998) Handbook on methods for climate change impact assessment and adaptation strategies. United Nations Environment Programme, Nairobi, and Institute for Environmental Studies, vrije Universiteit, Amsterdam

Fünfgeld H, Lonsdale K, Bosomworth K (2019) Beyond the tools: supporting adaptation when organisational resources and capacities are in short supply. Clim Chang. https://doi.org/10.1007/s10584-018-2238-7

Gardiner EP, Herring DD, Fox JF (2019) The U.S. Climate Resilience Toolkit: evidence of progress. Climatic Change. https://doi.org/10.1007/s10584-018-2216-0

Gilroy K, Jeuken A (2018) Collaborative risk informed decision analysis: a water security case study in the Philippines. Climate Services 11:62-71.https://doi.org/10.1016/j.cliser.2018.04.002

Groves DG, Lempert RJ (2007) A new analytic method for finding policy-relevant scenarios. Glob Environ Chang 17:73-85. https://doi.org/10.1016/j.gloenvcha.2006.11.006

Haasnoot M, Kwakkel JH, Walker WE, ter Maat J (2013) Dynamic adaptive policy pathways: a method for crafting robust decisions for a deeply uncertain world. Glob Environ Chang 23:485-498. https://doi. org/10.1016/j.gloenvcha.2012.12.006

Hall JW, Lempert RJ, Keller K et al (2012) Robust climate policies under uncertainty: a comparison of Robust Decision Making and Info-Gap methods. Risk Anal 32:1657-1672. https://doi.org/10.1111/j.15396924.2012.01802.x

Hasse C, Kind C (2019) Updating an existing online adaptation support tool: insights from an evaluation. Clim Chang. https://doi.org/10.1007/s10584-018-2166-6

Haunschild R, Bornmann L, Marx W (2016) Climate change research in view of bibliometrics. PLoS One 11: e0160393. https://doi.org/10.1371/journal.pone.0160393

Hewitson B, Waagsaether K, Wohland J et al (2017) Climate information websites: an evolving landscape. WIREs Clim Change 8:UNSP e470. https://doi.org/10.1002/wcc.470

Hulme M, Dessai S (2008) Predicting, deciding, learning: can one evaluate the 'success' of national climate scenarios? Environ Res Lett 3:045013. https://doi.org/10.1088/1748-9326/3/4/045013

Hulme M, Jenkins GJ (1998) Climate change scenarios for the United Kingdom: scientific report. UKCIP Technical Report 1. Climatic Research Unit, University of East Anglia, Norwich

Hulme M, Jenkins G, Lu X et al (2002) Climate change scenarios for the United Kingdom: the UKCIP02 scientific report. Tyndall Centre for Climate Research, University of East Anglia, Norwich

Jones RN, Preston BL (2011) Adaptation and risk management. WIREs Clim Chang 2:296-308. https://doi. org/10.1002/wcc. 97

Khan MR, Timmons JR (2013) Adaptation and international climate policy. WIREs Clim Chang 4:171-189. https://doi.org/10.1002/wcc.212

Kirchhoff CJ, Lemos MC, Dessai S (2013) Actionable knowledge for environmental decision making: broadening the usability of climate science. Ann Rev Environ Resour 38:393-414. https://doi.org/10.1146 /annurev-environ-022112-112828

Klink J, Koundinya V, Kies K et al (2017) Enhancing interdisciplinary climate change work through comprehensive evaluation. Clim Risk Manag 15:109-123. https://doi.org/10.1016/j.crm.2016.11.003

Korteling B, Dessai S, Kapelan Z (2013) Using Information-Gap Decision Theory for water resources planning under severe uncertainty. Water Resour Manag 27:1149-1172. https://doi.org/10.1007/s11269-012-0164-4 
Kwadijk JCJ, Haasnoot M, Mulder JPM et al (2010) Using adaptation tipping points to prepare for climate change and sea level rise: a case study in the Netherlands. WIREs Clim Chang 1:729-740. https://oi. org/10.1002/wcc.64

Kwakkel JH, Haasnoot M, Walker WE (2016) Comparing robust decision making and dynamic adaptive policy pathways for model-based decision support under deep uncertainty. Environ Model Softw 86:168-183. https://doi.org/10.1016/j.envsoft.2016.09.017

Lane DE, Mercer Clarke C, Forbes DL, Watson P (2013) The gathering storm: managing adaptation to environmental change in coastal communities and small islands. Sustain Sci 8:469-489

Laudien R, Boon E, Goosen H et al (2019) The Dutch adaptation web portal: seven lessons learnt from a coproduction point of view. Clim Chang. https://doi.org/10.1007/s10584-018-2179-1

Leitch AM, Palutikof JP, Rissik D et al (2019) Co-development of a climate change decision support system through engagement with stakeholders. Clim Chang. https://doi.org/10.1007/s10584-019-02401-0

Lemos MC, Morehouse BJ (2005) The co-production of science and policy in integrated climate assessments. Glob Environ Chang 15:57-68. https://doi.org/10.1016/j.gloenvcha.2004.09.004

Lemos MC, Kirchhoff C, Ramprasad V (2012) Narrowing the climate information usability gap. Nat Clim Chang 2:789-794. https://doi.org/10.1038/NCLIMATE1614

Lenderink G, van den Hurk BJJM, Tank AMGK (2014) Preparing local climate change scenarios for the Netherlands using resampling of climate model output. Environ Res Lett 9:115008. https://doi. org/10.1088/1748-9326/9/11/115008

Lim B, Spanger-Siegfried E, Burton I et al (2004) Adaptation policy frameworks for climate change: developing strategies, policies and measures. Cambridge University Press, Cambridge

Lin BB, Capon T, Langston A et al (2017) Adaptation pathways in coastal case studies: lessons learned and future directions. Coast Manag 45:384 405. https://doi.org/10.1080/08920753.2017.1349564

Matrosov ES, Woods AM, Harou JJ (2013) Robust Decision Making and Info-Gap Decision Theory for water resource system planning. J Hydrol 494:43-58. https://doi.org/10.1016/j.jhydrol.2013.03.006

Mattern K, Giannini V, Downing C et al (2018) Sharing adaptation knowledge across Europe: evidence for the evaluation of Climate-ADAPT. European Topic Centre on Climate Change impacts, Vulnerability and Adaptation (ETC/CCA) Technical Paper 2018/2. https://doi.org/10.25424/CMCC/EVIDENCE_ CLIMATE-ADAPT_EVALUATION_2018

McClure L, Baker D (2018) How do planners deal with barriers to climate change adaptation? A case study in Queensland, Australia. Landscape Urban Plan 173:81-88. https://doi.org/10.1016/j. landurbplan.2018.01.012

Measham TG, Preston BL, Smith TF et al (2011) Adapting to climate change through local municipal planning: barriers and challenges. Mitig Adapt Strateg Glob Chang 16:889-909. https://oi.org/10.1007/s11027-011-9301-2

Moser SC, Coffee J, Seville A (2017) Rising to the challenge, together: a review and critical assessment of the state of the US climate adaptation field. A report prepared for the Kresge Foundation, Troy. https://kresge. org/sites/default/files/library/rising_to the_challenge_together_linked_0.pdf. Accessed 8 Aug 2018

Moss RH, Meehl GA, Lemos MC et al (2013) Hell and high water: practice-relevant adaptation science. Science 342(6159):696-698. https://doi.org/10.1126/science.1239569

Murphy J, Sexton D, Jenkins G (2010) UK Climate Projections science report: climate change projections. UK Met Office Hadley Centre, Exeter

Newman JP, Holger RM, Riddell GA et al (2017) Review of literature on decision support systems for natural hazard risk reduction: current status and future research directions. Environ Model Softw 96:378-409. https://doi.org/10.1016/j.envsoft.2017.06.042

Nkoana EM, Verbruggen A, Huge J (2018) Climate change adaptation tools at the community level: an integrated literature review. Sustainability 10:796. https://doi.org/10.3390/su10030796

Palutikof JP, Rissik D, Webb S et al (2019a) CoastAdapt: an adaptation decision support framework for Australia's coastal managers. Clim Chang. https://doi.org/10.1007/s10584-018-2200-8

Palutikof JP, Leitch AM, Rissik D et al (2019b) Overcoming knowledge barriers to adaptation using a decision support framework. Clim Chang. https://doi.org/10.1007/s10584-018-2177-3

Palutikof JP, Street RB, Gardiner EP (2019c) Looking to the future: guidelines for decision support as adaptation practice matures. Clim Chang. https://doi.org/10.1007/s10584-019-02404-x

Perkins B, Ojima D, Corell R (2007) A survey of climate change adaptation planning. The H. John Heinz III Center for Science, Economics and the Environment, Washington DC

Porter JJ, Dessai S (2017) Mini-me: why do climate scientists misunderstand users and their needs? Environ Sci Pol 77:9-14. https://doi.org/10.1016/j.envsci.2017.07.004

Porter JJ, Demeritt D, Dessai S (2015) The right stuff? Informing adaptation to climate change in British local government. Glob Environ Chang 35:411-422. https://doi.org/10.1016/j.gloenvcha.2015.10.004

Prokopy LS, Carlton JS, Haigh T et al (2017) Useful to usable: developing usable science for agriculture. Clim Risk Manag 15:1-7. https://doi.org/10.1016/j.crm.2016.10.004 
Prutsch A, Grothmann T, McCallum S et al (eds) (2014) Climate change adaptation manual: lessons learned from European and other industrialised countries. Routledge, Abingdon

Ranger N, Reeder T, Lowe J (2013) Addressing 'deep' uncertainty over long-term climate in major infrastructure projects: four innovations of the Thames Estuary 2100 Project. EURO J Decis Process 1:233-262. https://doi.org/10.1007/s40070-013-0014-5

Reiter D, Meyer W, Parrott L et al (2018) Increasing the effectiveness of environmental decision support systems: lessons from climate change adaptation projects in Canada and Australia. Reg Environ Chang 18:11731184. https://doi.org/10.1007/s10113-017-1255-9

Rodenhuis D, Bennett KE, Werner AT et al (2009) Climate overview 2007: hydroclimatology and future climate impacts in British Columbia. Pacific Climate Impacts Consortium, University of Victoria, Victoria

Sanderson T, Hertzler G, Capon T, Hayman P (2016) A real options analysis of Australian wheat production under climate change. Aust J Agric Resour Econ 60:79-96. https://doi.org/10.1111/1467-8489.12104

Stratus Consulting (1999) Compendium of decision tools to evaluate strategies for adaptation to climate change. Prepared for UNFCCC Secretariat, Bonn. http://www.start.org/Projects/AIACC_Project/resources/ele_lib_ docs/adaptation decision tools.pdf. Accessed 18 July 2018

Street RB (2016) Towards a leading role on climate services in Europe: a research and innovation roadmap. Climate Services 1:2-5. https://doi.org/10.1016/j.cliser.2015.12.001

Street R, Karali E, Mattern K et al (2015) Overview of climate change adaptation platforms in Europe. EEA Technical Report No 5/2015. European Environment Agency, Copenhagen

Street RB, Pringle P, Capela Lourenço TC, Nicolletti M (2019) Transferability of decision-support tools. Clim Chang. https://doi.org/10.1007/s10584-018-2263-6

Swart RJ, de Bruin K, Dhenain S et al (2017) Developing climate information portals with users: promises and pitfalls. Clim Serv 6:12-22. https://doi.org/10.1016/j.cliser.2017.06.008

Tang S, Dessai S (2012) Usable science? The UK Climate Projections 2009 and decision support for adaptation planning. Weather Clim Soc 4:300-313. https://doi.org/10.1175/WCAS-D-12-00028.1

TCFD (2017) Final report: recommendations of the task force on climate-related financial disclosure. https:/www.fsb-tcfd.org/wp-content/uploads/2017/06/FINAL-2017-TCFD-Report-11052018.pdf. Accessed 15 Feb 2019

Tompkins EL, Adger WN, Boyd E et al (2010) Observed adaptation to climate change: UK evidence of transition to a well-adapting society. Glob Environ Chang 20:627-635. https://doi.org/10.1016/j.gloenvcha.2010.05.001

Tonmoy FN, Rissik D, Palutikof JP (2019) A three-tier risk assessment process for climate change adaptation planning at a local scale. Clim Chang. https://doi.org/10.1007/s10584-019-02367-z

Torresan S, Critto A, Rizzi J et al (2016) DESYCO: a decision support system for the regional risk assessment of climate change impacts in coastal zones. Ocean Coast Manage 120:49-63. https://doi.org/10.1016/j. ocecoaman.2015.11.003

UKCIP (2004) Costing the impacts of climate change in the UK: implementation report. UKCIP, Oxford. https://www.ukcip.org.uk/wp-content/PDFs/Costings_Implementation.pdf. Accessed 14 Feb 2019

UKCIP (2013) The UKCIP Adaptation Wizard v 4.0. UKCIP, Oxford

UNFCCC (2002) Annotated guidelines for the preparation of national adaptation programmes of action. UNFCCC Secretariat, Bonn. https:/unfccc.int/resource/docs/publications/annguid_e.pdf. Accessed 18 July 2018

UNFCCC (2005) Compendium on methods and tools to evaluate impacts of, and vulnerability and adaptation to, climate change. UNFCCC Secretariat, Bonn. https://unfccc.int/files/adaptation/methodologies for/vulnerability_and_adaptation/application/pdf/200502_compendium_methods_tools_2005.pdf. Accessed 18 July 2018

Vaughan C, Dessai S (2014) Climate services for society: origins, institutional arrangements and design elements for an evaluation framework. WIREs Clim Chang 5:587-603. https://doi.org/10.1002/wcc.290

Webb R, Rissik D, Petheram L et al (2019) Co-designing adaptation decision support: meeting common and differentiated needs. Clim Chang. https://doi.org/10.1007/s10584-018-2165-7

Wilby RN, Dessai S (2010) Robust adaptation to climate change. Weather 65:180-185 https://doi-org. libraryproxy.griffith.edu.au/10.1002/wea.543

Willows RI, Connell RK (eds) (2003) Climate adaptation: risk, uncertainty and decision-making. UKCIP Technical Report. UKCIP, Oxford

Publisher's note Springer Nature remains neutral with regard to jurisdictional claims in published maps and institutional affiliations. 